\title{
Dynamic lighting systems in psychogeriatric care facilities in the Netherlands : a quantitative and qualitative analysis of stakeholders' responses and applied technology
}

Citation for published version (APA):

Aarts, M. P. J., Aries, M. B. C., Straathof, J., \& van Hoof, J. (2015). Dynamic lighting systems in psychogeriatric care facilities in the Netherlands : a quantitative and qualitative analysis of stakeholders' responses and applied technology. Indoor and Built Environment, 24(5), 617-630. https://doi.org/10.1177/1420326X14532387

\section{Document license:}

TAVERNE

DOI:

10.1177/1420326X14532387

Document status and date:

Published: 01/01/2015

\section{Document Version:}

Publisher's PDF, also known as Version of Record (includes final page, issue and volume numbers)

\section{Please check the document version of this publication:}

- A submitted manuscript is the version of the article upon submission and before peer-review. There can be important differences between the submitted version and the official published version of record. People interested in the research are advised to contact the author for the final version of the publication, or visit the $\mathrm{DOI}$ to the publisher's website.

- The final author version and the galley proof are versions of the publication after peer review.

- The final published version features the final layout of the paper including the volume, issue and page numbers.

Link to publication

\footnotetext{
General rights

- You may freely distribute the URL identifying the publication in the public portal. follow below link for the End User Agreement:

www.tue.nl/taverne

\section{Take down policy}

If you believe that this document breaches copyright please contact us at:

openaccess@tue.nl

providing details and we will investigate your claim.
}

Copyright and moral rights for the publications made accessible in the public portal are retained by the authors and/or other copyright owners and it is a condition of accessing publications that users recognise and abide by the legal requirements associated with these rights.

- Users may download and print one copy of any publication from the public portal for the purpose of private study or research.

- You may not further distribute the material or use it for any profit-making activity or commercial gain

If the publication is distributed under the terms of Article 25fa of the Dutch Copyright Act, indicated by the "Taverne" license above, please 


\title{
Dynamic lighting systems in psychogeriatric care facilities in the Netherlands: A quantitative and qualitative analysis of stakeholders' responses and applied technology
}

Indoor and Built Environment 2015, Vol. 24(5) 617-630 (C) The Author(s) 2014 Reprints and permissions: sagepub.co.uk/ journalsPermissions.nav DOI: $10.1177 / 1420326 \times 14532387$ ibe.sagepub.com

(SAGE

\author{
Mariëlle P. J. Aarts ${ }^{1}$, Myriam B. C. Aries ${ }^{1}$, \\ Jochem Straathof ${ }^{1}$ and Joost van Hoof ${ }^{2}$
}

\begin{abstract}
Long-term care facilities are currently installing dynamic lighting systems with the aim to improve the well-being and behaviour of residents with dementia. The aim of this study was to investigate the implementation of dynamic lighting systems from the perspective of stakeholders and the performance of the technology. Therefore, a questionnaire survey was conducted with the management and care professionals of six care facilities. Moreover, light measurements were conducted in order to describe the exposure of residents to lighting. The results showed that the main reason for purchasing dynamic lighting systems lied in the assumption that the well-being and day/night rhythmicity of residents could be improved. The majority of care professionals were not aware of the reasons why dynamic lighting systems were installed. Despite positive subjective ratings of the dynamic lighting systems, no data were collected by the organizations to evaluate the effectiveness of the lighting. Although the care professionals stated that they did not see any large positive effects of the dynamic lighting systems on the residents and their own work situation, the majority appreciated the dynamic lighting systems more than the old situation. The light values measured in the care facilities did not exceed the minimum threshold values reported in the literature. Therefore, it seems illogical that the dynamic lighting systems installed in the researched care facilities will have any positive health effects.
\end{abstract}

\section{Keywords}

Dementia, Cost/benefit analysis, Nursing home, Light therapy, Ambient bright light, Care professionals

Accepted: 29 March 2014

\section{Introduction}

Light therapy covers an area in medicine where medical sciences meet the realms of physics, engineering and technology. ${ }^{1-3}$ One of the ways to administer light therapy is by increasing general illuminance levels in buildings, the so-called ambient bright light, using a combination of special luminaires, lights and control technology. Over a decade ago, van Someren et al. ${ }^{4}$ demonstrated that exposing people with dementia to bright light led to a re-synchronization of their disturbed activity patterns. Since then, the role of light has obtained an additional dimension for all human beings but especially for people with Alzheimer's disease and other forms of dementia. From the initial

\footnotetext{
${ }^{1}$ Department of the Built Environment, Eindhoven University of Technology, Eindhoven, The Netherlands

${ }^{2}$ Centre for Healthcare and Technology, Fontys University of Applied Sciences, Eindhoven, The Netherlands

Corresponding author:

Mariëlle P. J. Aarts, Department of the Built Environment, Eindhoven University of Technology, Den Dolech 2, 5612 AZ Eindhoven, The Netherlands.

Email: m.p.j.aarts@tue.nl
} 
orientation on vision, research activities expanded to a non-image forming (NIF) area. The novelty of NIF effects was the finding of a direct neurological connection between the intrinsically photosensitive retinal ganglion cells in the eye, and the centre of our circadian timing system which lies in the hypothalamic suprachiasmatic nuclei..$^{5-7}$ This meant a direct relation between environmental light and typical related aspects like cognition, mood, behaviour and sleep. The long-term, multicenter, double-blind, randomized placebo-controlled trial, performed by Riemersma-van der Lek on the influence of bright light and melatonin supplementation on older people with dementia, concluded that 'light has a modest benefit in improving some cognitive and noncognitive symptoms of dementia. To counteract the adverse effect of melatonin on mood, it is recommended only in combination with light'. ${ }^{8}$ Although the evidence base of ambient bright light is growing rapidly, ${ }^{2,3}$ the conclusion of a Cochrane systematic review by Forbes et al. ${ }^{9}$ was that due to the lack of sufficient numbers of randomized controlled trials, there is not enough evidence to support the claimed benefits of bright light therapy for people with dementia. Also, Shikder et al. ${ }^{10}$ concluded that the implementation of therapeutic aspects of lighting in buildings is still debatable due to an insufficient number of relevant investigations and the robustness of their findings.

There is an increasing interest within the building community for the non-visual aspects of light. ${ }^{11}$ This has led to the emergence of the so-called dynamic bright light solutions. The underlying assumption of such systems is that human beings evolved in daylight conditions, and that the dynamic component in the emission of light contributes to the positive effects of the ambient bright light systems (Figure 1). In addition, the required illuminance levels are much higher than average, i.e. values of two to five times higher than normal indoor conditions in group living rooms of care facilities. In addition, so is the (correlated) colour temperature of the light, which should exceed $5000 \mathrm{~K}$. This is much higher than the normal values that lie between $2700 \mathrm{~K}$ and $4000 \mathrm{~K}$. In practice, both illuminance and colour temperature are controlled through dedicated software. Generally, only the main luminaire in the living room is steered via a dynamic protocol. In practice, the lighting follows a protocol with instead of one, two peak moments. The reason is that the time schedule of people living in a care facility normally exists of a rest period after lunch time. As there is no validated set of algorithms, which can be used in these lighting systems, and there is practically no evidence regarding the relative effects of static versus dynamic lighting protocols, ${ }^{12-14}$ there is still plenty of room for innovation and research. Instead of evidence-based practice, we see the results of market-based research: care facilities are purchasing and installing new lighting technologies because of their supposed health benefits.

Manufacturers and dealers of dynamic lighting systems (DLSs) claim that the lighting has a positive effect on the behaviour and the sleep-wake rhythm of people with dementia. The vast majority of scientific literature, as known to the authors, studied the effects of static lighting systems. When searching for the influence of DLSs on (older) people with dementia, only one scientific study was identified ${ }^{15}$ : a small-scale pilot study conducted in two living rooms $n=10$ control, $n=10$ intervention. The results showed that the activity level in the intervention group decreased significantly during both night-time and daytime compared to baseline. The ratio between day and night-time activity remained the same. The research team concluded that more research is necessary before the results can be fully interpreted. The maximum correlated colour temperature of the lighting was only $4600 \mathrm{~K}$. The maximum illuminance was $12001 \mathrm{x}$, but no indication of the measurement position or direction was given. Most likely, the researchers reported horizontal illuminance values.

We see the emergence of DLSs among a range of buildings, for instance, in schools, ${ }^{16,17}$ healthcare buildings $^{2,15}$ and offices. ${ }^{18}$ Although the effects of these DLSs are often unclear, the additional initial costs and energy costs are significant. These issues are very relevant as budgets in long-term care are under extreme pressure due to political choices and prioritization. Although the evidence regarding the positive impact of light on the well-being of especially older people (with dementia) or persons with other neurological diseases are hopeful but not convincingly and scientifically affirmed, ${ }^{9}$ these insights are already being converted to implementable solutions. Applying light therapy as an instrument for care has obvious benefits. It is non-invasive, non-pharmacological, it is relatively cheap in maintenance and it has a high level of intuitive use creating a low threshold for acceptance. ${ }^{2}$ Two additional incentives for the purchase of (dynamic) lighting systems are (1) that persons with dementia do not venture outdoors as much as healthy younger adults, due to mobility impairments, and (2) inside their homes they are exposed to light levels which are insufficient. ${ }^{19,20}$

The goal of the current study is to investigate the implementation of DLSs installed in psychogeriatric care facilities, by addressing both the subjective effects on the residents as well as on the professional caregivers. Also the role of the different stakeholders in the decision process is considered. The following questions are addressed:

1. What was the main reason for installing the DLSs and can the benefits of the system counterbalance the costs? 


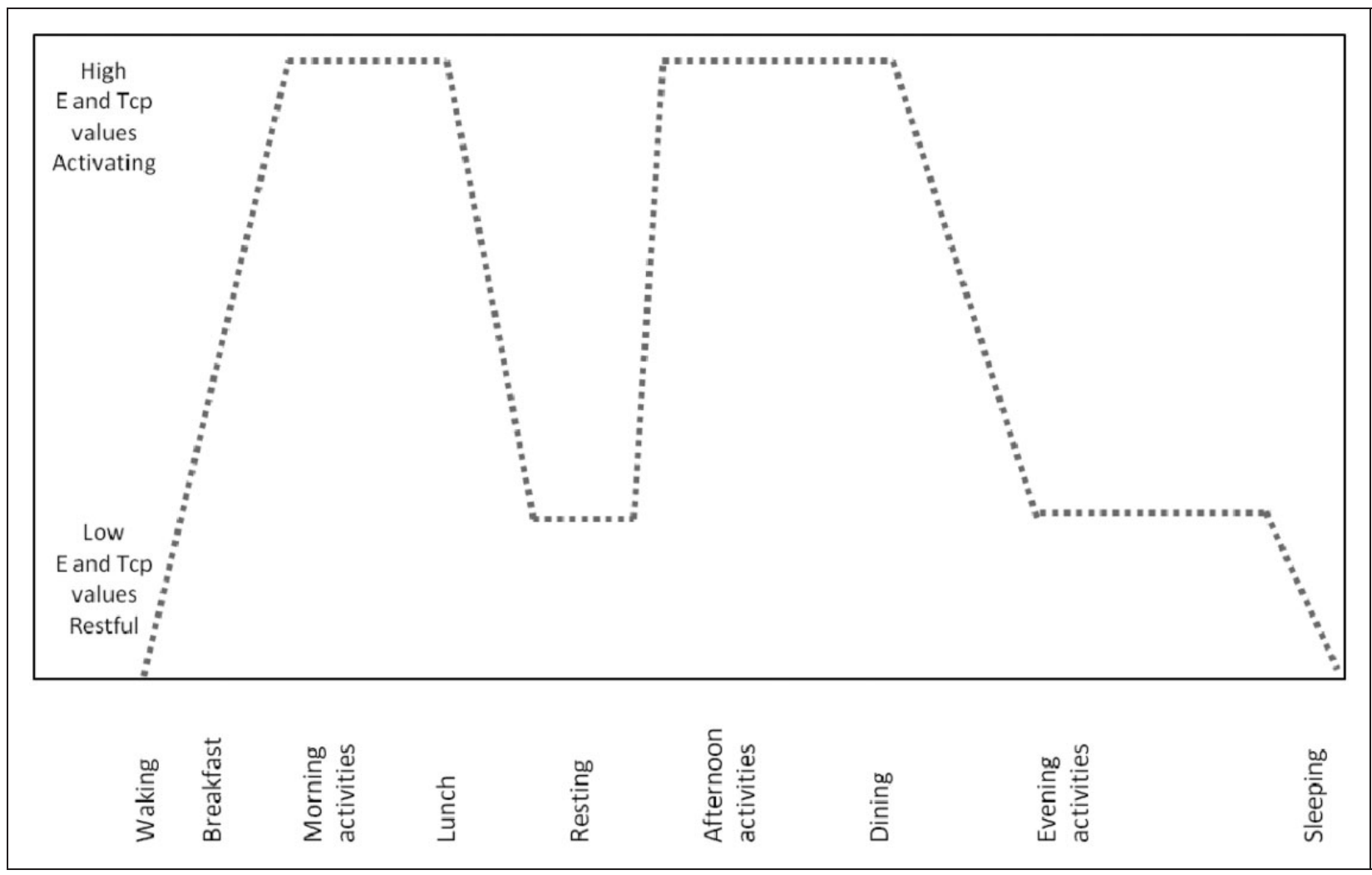

Figure 1. Schematic representation of a dynamic lighting protocol in relation to daytime activities.

2. Are care professionals and care facility managers aware of the psychological and physiological benefits that these lighting systems should achieve?

3. Did care facilities monitor the health effects on residents in the pre- and post-installation phases?

4. What are the expectations of the care professionals of the effects on the behavioural symptoms of their residents?

5. How do care professionals perceive the DLSs?

6. Do the installed lighting levels meet the preliminary threshold levels stated in the literature? In other words: are the indoor light levels sufficiently high to yield effects?

\section{Methodology}

At the start of this study, an inventory was made on the number of psychogeriatric care facilities in the Netherlands where DLSs were installed. Because there is no general network to refer to and because care facilities are responsible for their own financing of lighting equipment, the authors' network existing of lighting advisors, electrical engineers, health care workers, policy workers and researchers was consulted to determine the facilities that have a kind of DLS installed. Moreover, the network of the KIEN Foundation
(Stichting Knooppunt Innovatie Elektrotechniek Nederland), Eindhoven University of Technology, three Dutch companies specialized in light and health solutions (MediluX, Davita Nederland and Meutzner Licht Design) and the Dutch Light and Health Research Foundation (SOLG) was used. In total, 11 (psycho)geriatric care facilities were identified as having DLSs installed in their communal living rooms. All facilities were asked to participate in this study, of which six responded positively. From those six, a questionnaire was distributed to the director/ manager of the living rooms equipped with the DLS, in order to gain insight on the costs and potential benefits of the lighting systems. Of these six facilities, four gave permission to conduct a survey among the care professionals and to conduct light measurements in the living rooms. The light measurements in the care facilities were performed on the same day as the survey among the care professionals.

\section{Surveys}

In this research, a stakeholder approach was chosen for the analysis of health care environments, identifying director/managers and care professionals as main stakeholders. ${ }^{21}$ Psychogeriatric residents were not included in this study, as they were not the main 
stakeholder group that this study focuses on. For this study, two different questionnaire-like surveys are used. No validated questionnaire could be used due to the specific questions. Therefore, questionnaires were specially designed for this research. The first one, questionnaire A, was set up to be filled out by the director/ managers of the six care facilities. The second one, questionnaire $\mathrm{B}$, was distributed among the care professionals of four facilities.

\section{Questionnaire A: An inventory among directors}

The questionnaire was filled out by the director of care facilities distributed over the Netherlands, namely in Eindhoven, Gilze-Rijen, Lelystad, Maastricht, Huizen and Egmond aan Zee. The goal of this questionnaire was to answer the following three initial questions:

1. What was the main reason for installing the DLSs and can the benefits of the system counterbalance the costs?

2. Are care professionals and care facility managers aware of the psychological and physiological benefits DLSs should achieve?

3. Did care facilities monitor the health effects on residents in the pre- and post-installation phases?

This questionnaire was conducted via a telephone interview for which an appointment was made. This was done to ensure that all the questions were correctly understood. The communication with the participants of the care facilities all went via the same researcher (JS).

\section{Questionnaire B: Perception of the lighting by care professionals}

This questionnaire was distributed among the care professionals of the four care facilities in Eindhoven, GilzeRijen, Lelystad and Egmond aan Zee. In the facility in Maastricht, research was already performed earlier and published ${ }^{17}$ and the facility in Huizen conducted a separate effect study. For reason of anonymity, the homes are referred to as A, B, C and D (in random order). The goal of this questionnaire was to answer the two following questions:

1. What are the expectations of the care professionals of the effects on the behavioural symptoms of their residents?

2. How do care professionals perceive the DLSs?

The questionnaire existed of several general questions concerning their experience with the system itself, followed by questions about whether the lighting was perceived as comfortable. It ended with questions regarding their own well-being as well as the perceived behaviour differences among the residents.

In total, 21 female care professionals (five in facility A, six in facility B, seven in facility $\mathrm{C}$ and three in facility D) filled out the questionnaire. All worked at least $12 \mathrm{~h}$ per week and had different shifts on a weekly basis. Seven people were aged less than 35 years, six were aged between 35 and 50 years and eight were over 50 years old. A total of 17 professionals already worked at the same facility before installing DLSs.

\section{Field measurements and DLSs}

By conducting field measurements in four living rooms of different care facilities, the final question should be answered:

1. Do the installed lighting levels meet the preliminary threshold levels stated in the literature?

In four living rooms, lighting measurements were performed to measure the illuminance (E) and the colour temperature of light $\left(\mathrm{T}_{\mathrm{cp}}\right)$ people were exposed to (vertically, at eye level, at a height of $1.2 \mathrm{~m}$ ) (Figures 2 to 5). In the four living rooms, light measurements were conducted near the most frequently used sitting positions in the communal living room where the DLS was installed. Measurements were performed under two different light conditions: (1) high $\mathrm{E}$ and high $\mathrm{T}_{\mathrm{cp}}$, and (2) low $\mathrm{E}$ and low $\mathrm{T}_{\mathrm{cp}}$. Since all living rooms have daylight openings (windows), there was a contribution of daylight access on the indoor light levels during daytime. In living room $\mathrm{C}$, no dim period occurred and, therefore, no data are available. All measurements were conducted in May 2012. Although the time of year should not influence the light values of the DLSs, it does influence the contribution of daylight. In May, relatively high daylight values can be measured. None of the DLSs used daylight controls, meaning that when the daylight values reach a required value, the DLSs dimmed down. The illuminance and the $\mathrm{T}_{\mathrm{cp}}$ were measured by the Konica Minolta Incident Color Meter type CL-200.

\section{Results}

Three brands of DLSs were installed in the four living rooms. The manufacturers were Derungs, luminaire type Amadea in facility A, van Doorn, luminaire type Biosun in facility $\mathrm{C}$ and twice Philips, luminaire type Strato in facilities B and D (Figure 6). All systems were equipped with several tubular fluorescent light sources with two different $T_{c p}$ values, namely $2700 \mathrm{~K}$ and 


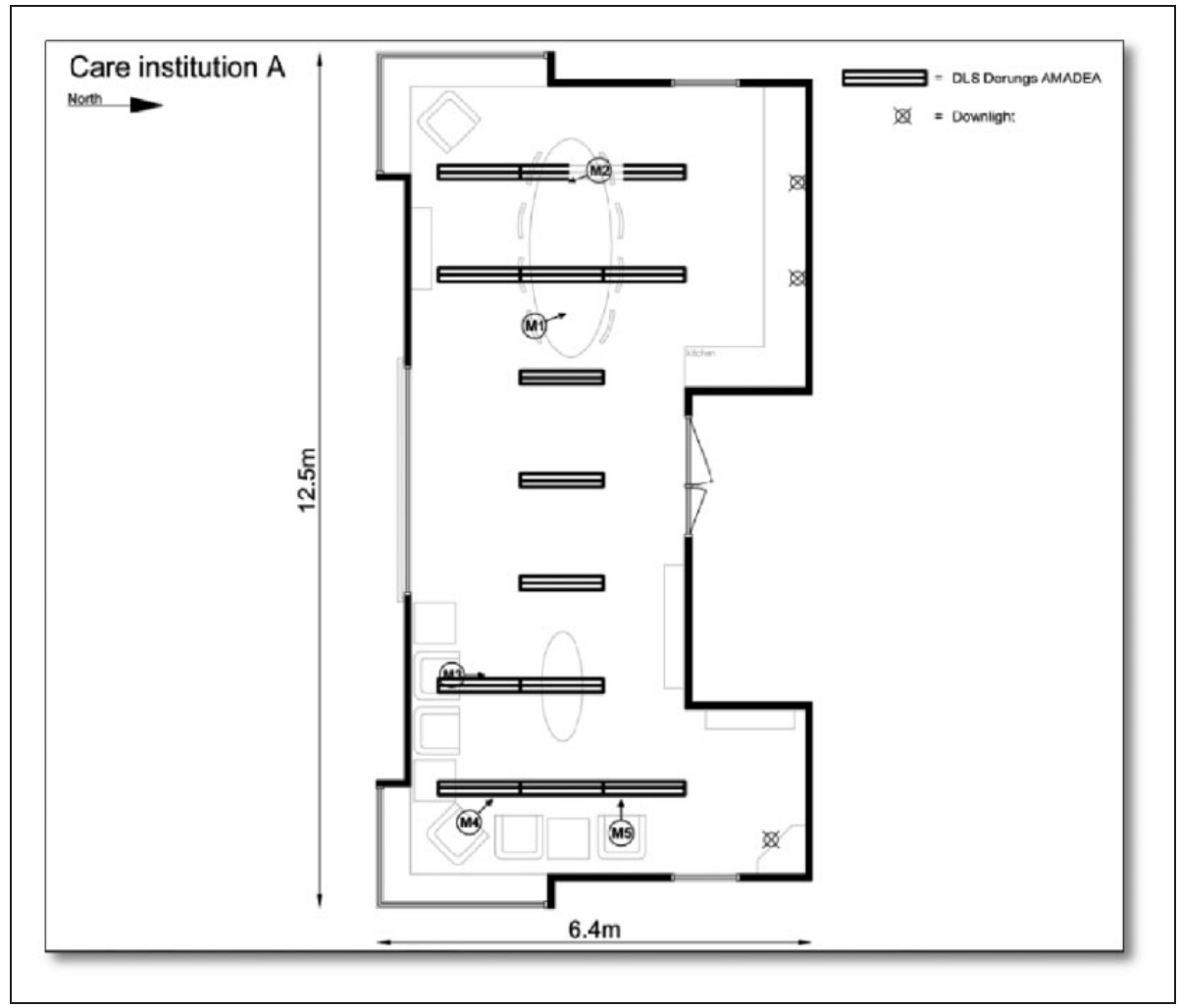

Figure 2. Layout living room and DLS locations care, facility A.

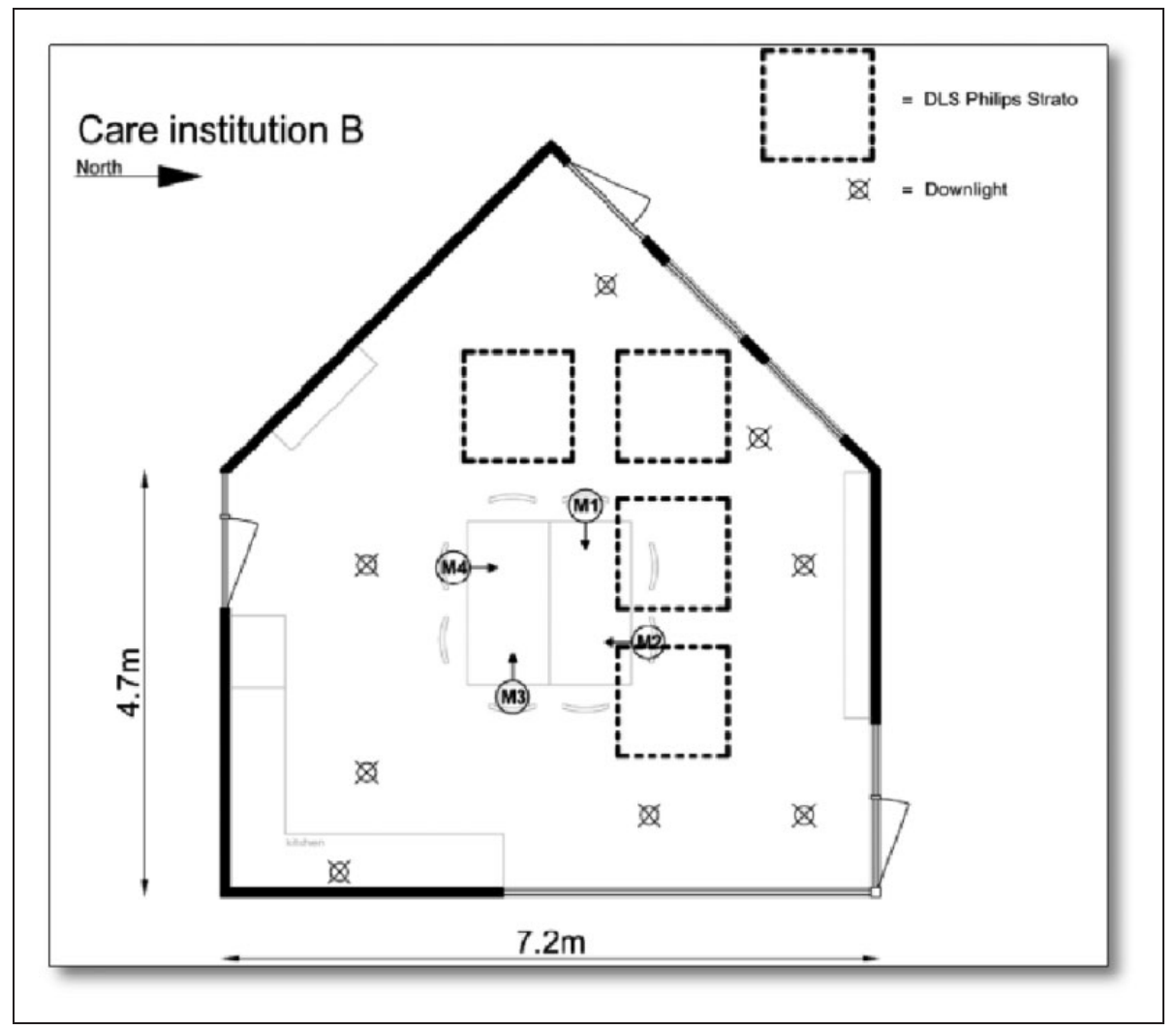

Figure 3. Layout living room and DLS locations care, facility B. 


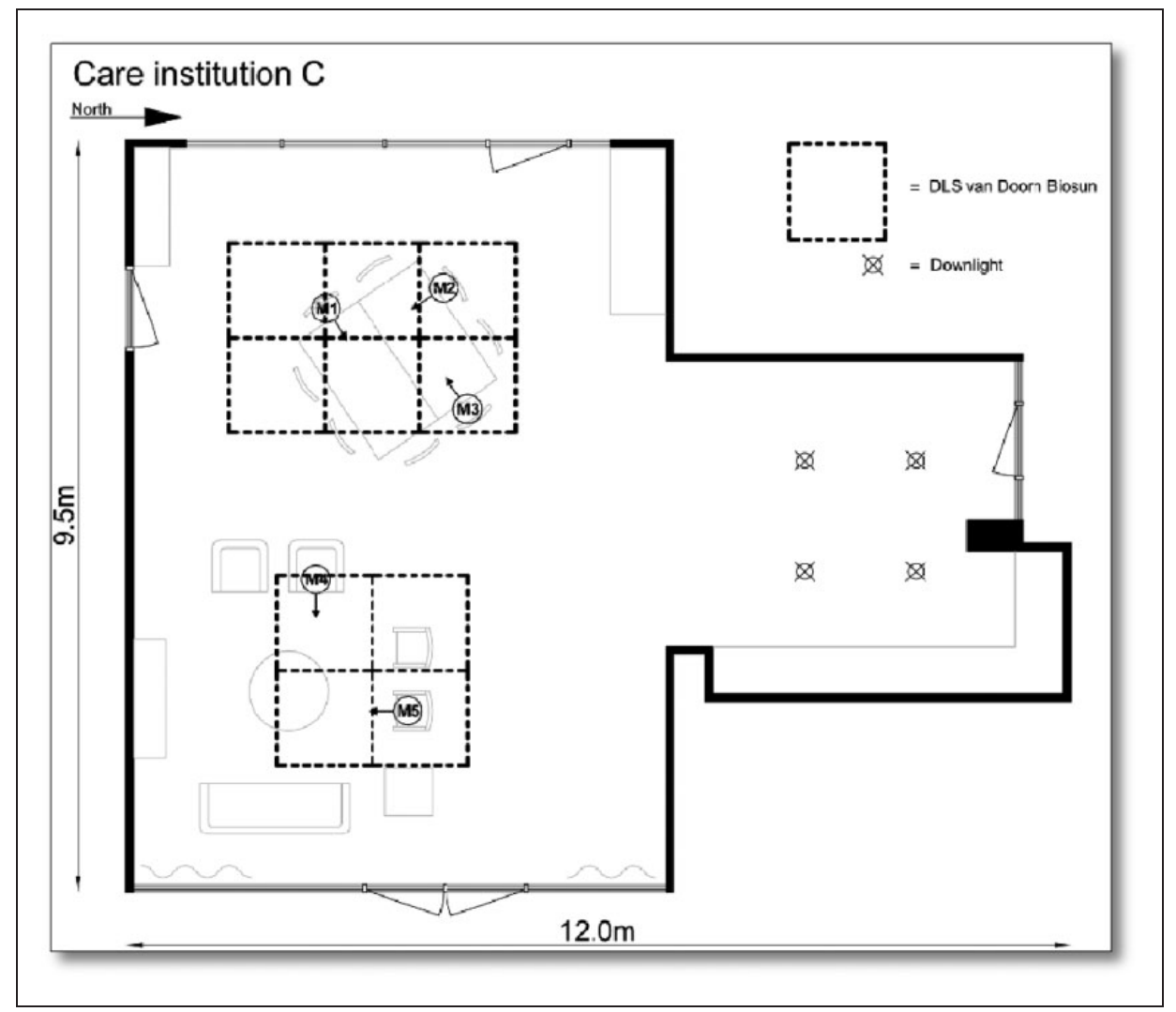

Figure 4. Layout living room and DLS locations care, facility C.

$6500 \mathrm{~K}$. By mixing light sources within the luminaire, a colour temperature between $2700 \mathrm{~K}$ and $6500 \mathrm{~K}$ can be achieved. In the living rooms of facilities A, B and D, all lighting scenarios were programmed to start in the morning at a low $\mathrm{E}$ and a low and warm $\mathrm{T}_{\mathrm{cp}}$. Until 09:00 h, these values gradually increased to the maximum values. After lunchtime, the values were again set to a low $\mathrm{E}$ and $\mathrm{T}_{\mathrm{cp}}$ for about $1 \mathrm{~h}$, with a final boost of high $\mathrm{E}$ and $\mathrm{T}_{\mathrm{cp}}$ until the end of the afternoon. At the end of the afternoon/beginning of the evening, the values gradually decreased towards the lower values again. In living room $\mathrm{C}$, no dynamic light scenario was implemented. Instead, a continuous high light level and $\mathrm{T}_{\mathrm{cp}}$ were provided by the DLSs.

\section{Questionnaire A: An inventory among directors}

What was the main reason for installing the lighting system and can the benefits of the system counterbalance the costs? The main reasons for purchasing DLSs are to improve the sleep-wake rhythm of the residents and their well-being in general (Table 1). All indirect effects like reduced costs of medication, reduced fall incidents and reduced work pressure for care professionals seem less important than the urge to create a pleasant living condition for older persons with dementia.

Three of the six managers were willing and able to share the costs of the purchased system. These costs varied from $€ 12,000$ to $€ 53,000$ per living room. The large differences can be explained by considering the size of the living room and the additional costs for installation. Also, the year the systems were installed demonstrated differences in costs; the first systems date from 2007 and were the most expensive. The latest stem from 2011 and were the least expensive. On the question 'if they would consider installing DLSs even without financial support', half of the managers responded positively (Figure 7). All three managers, who responded positively, purchased the system in 2011. The ones, who are not willing to purchase a DLS again, say it is too expensive without additional financial resources, and that the costs are too high given the benefits. These managers purchased the DLS in 2007.

Are care professionals and care facility managers aware of the psychological and physiological benefits DLSs should achieve? All six managers know that the lighting 


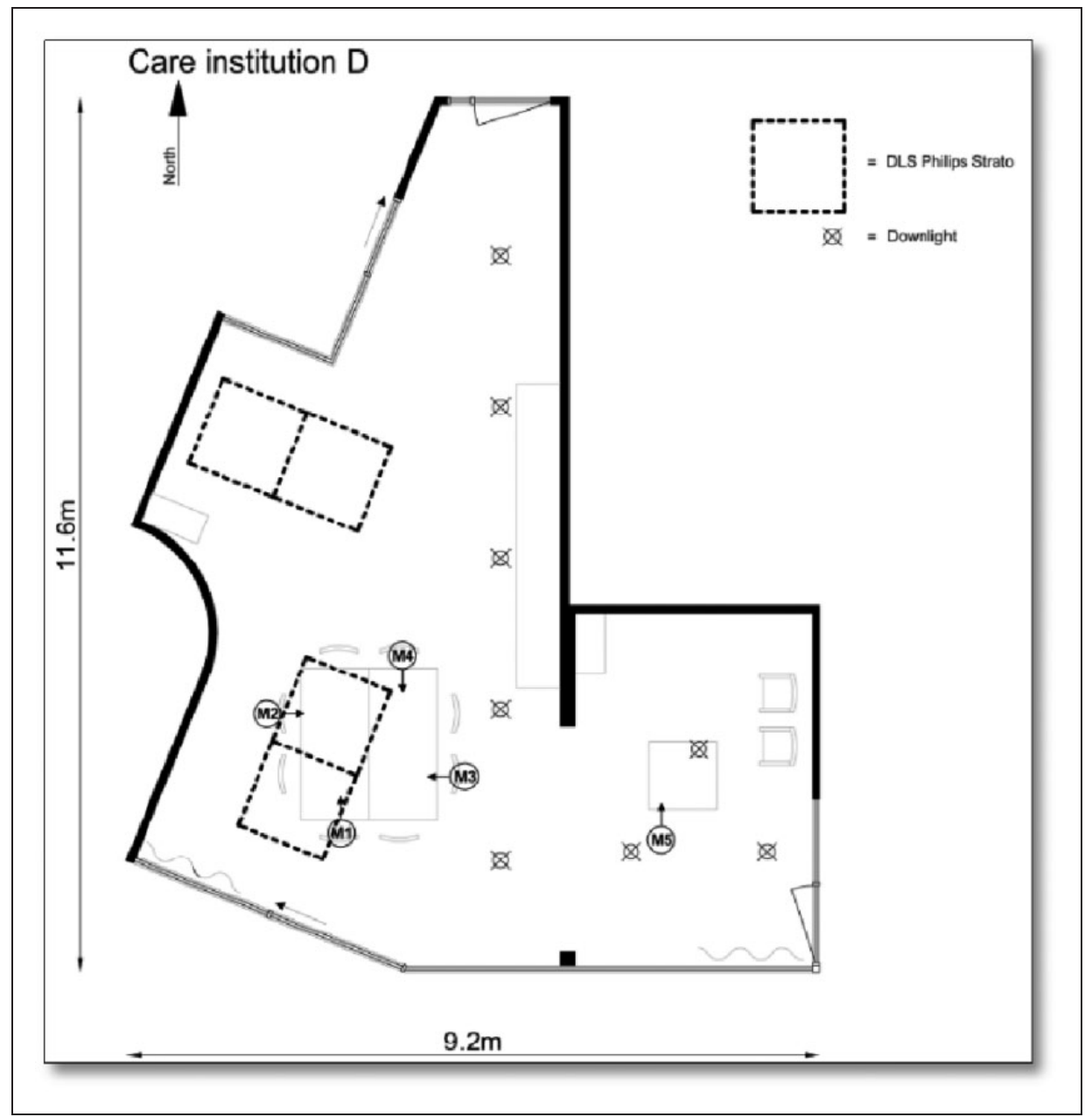

Figure 5. Layout living room and DLS locations care, facility D.

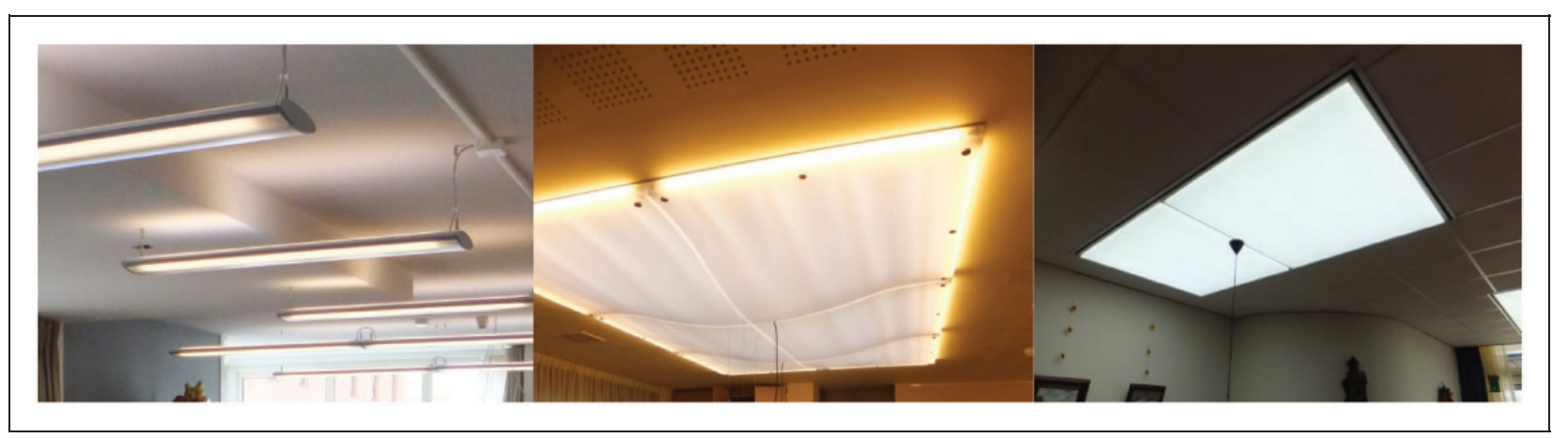

Figure 6. DLS from Derungs (left), van Doorn (middle) and Philips (right).

system can change the colour temperature and light level and that such systems are automatically controlled. In only one of the care facilities, regular meetings take place between managers and care professionals on the effects of the lighting. In four, information is supplied to the care professionals in an informal manner. In three care facilities, the lighting was installed relatively recently. In three of the four facilities, the care professionals cannot adjust any features of the DLSs themselves. There is only one nursing home (Facility C), where care professionals can make changes to the lighting. There are four different settings: (1) programmed fully automatic; (2) relaxation; (3) $100 \%$ switched on and (4) watching a movie. On the 
Table 1. Reason for purchasing DLSs ( $n=6$ facilities).

\begin{tabular}{ll}
\hline Reasons for purchasing DLSs & $\begin{array}{l}\text { Number of } \\
\text { facilities stating } \\
\text { this reason }\end{array}$ \\
\hline Improve sleep-wake rhythm of residents & 4 \\
Improve the well-being of residents & 4 \\
Improve behaviour of residents & 3 \\
Reduce number of fall incidents & 2 \\
Reduce the use of medication & 2 \\
Reduce the work pressure on care & 2 \\
professionals & 2 \\
Improve the atmosphere of the room & \\
\hline
\end{tabular}

DLSs: dynamic lighting systems.

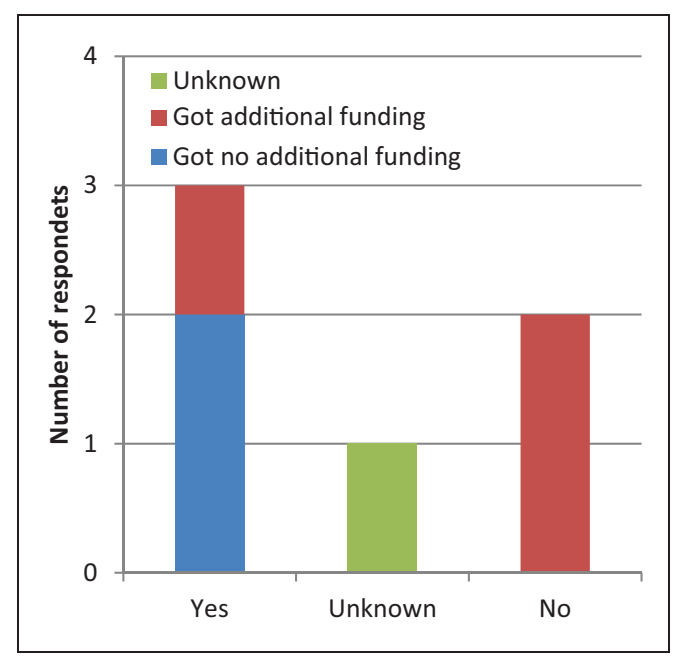

Figure 7. Willingness to purchase DLS again (with or without additional funding).

question if care professionals are aware of a lighting protocol, no one mentioned about the dynamic character of the lighting. In the facilities where care professionals cannot change the lighting, they noticed that the light switches on in the morning and switches off in the evening.

Did care facilities monitor the health effects of residents in the pre- and postinstallation phase? On the question whether health effects could be observed due to DLSs, based on pre- and post-installation parameters like fall incidents, medication use and sleep-wake rhythm, only one facility could provide numbers of fall incidents during the pre- and post-installation phases. These data, however, were not suitable for further analysis, as the organization moved from an older building to a newly built facility. So if effects where to be found, it would not be traceable whether this is due to the lighting or other changes in the living conditions of the residents. The three facilities that had installed the DLSs in 2011 did not have any pre- and post-values available (yet). Based on the lack of objective data, no analysis of potential health effects of the DLSs could be performed. Any suggestions made by the care organizations are, therefore, subjective instead of based on objective data gathered in a structured way.

\section{Questionnaire B: Perception of the lighting by care professionals}

Questionnaires were handed out to the care professionals, who worked in living rooms with DLSs mounted to the ceilings. In total, 21 questionnaires were filled out and returned: facility $\mathrm{A}, n=5$; facility $\mathrm{B}, n=6$; facility $\mathrm{C}, n=7$; and facility $\mathrm{D}, n=3$. Four out of 21 care professionals were not working at the facility before the DLSs were installed. That is why questions concerning the situation before and after installing DLSs were only considered for 17 employees.

What are the expectations of the care professionals of the effects on the behavioural symptoms of their residents and how do care professionals perceive the DLSs? The results of the questionnaires are listed per care facility in Table 2 . The number of respondents in facilities A, B, C and D were, respectively, 5, 6, 7 and 3 for the questions related to lighting. For the questions about 'effects on clients' and 'effects on care professional', only responses of people working before and after the installation of the DLSs were included (respectively 4, 4, 6 and 3 respondents).

In total, 14 of the 17 care professionals do not experience an improvement in their own behaviour or mood, as well as in the behaviour of the residents after installing the DLSs. A total of 12 care professionals consider the lighting as an improvement compared to the conventional (pre-implementation) situation. Six care professionals indicated that the visual performance improved. Of the 17 care professionals, 16 do not experience that the lighting is of influence on the use of sleep medication by residents. Five out of the 17 indicate that the amount of fall incidents is reduced and the activity during the day has increased (Figure 8). Three of these five have serious doubts whether these positive effects can be attributed to the installation of DLSs or other changes. While installing DLSs, wireless movement sensors, more active guidance, additional building renovation and several other changes might have been of influence. These subjective statements cannot be supported by objective data. 
Table 2. Results of the questionnaires among care professionals per care facility.

\begin{tabular}{|c|c|c|c|c|c|}
\hline & \multicolumn{5}{|l|}{ Care facility } \\
\hline & & A & B & $\mathrm{C}$ & $\mathrm{D}$ \\
\hline \multicolumn{6}{|l|}{ Lighting } \\
\hline \multirow[t]{3}{*}{ Illuminance level } & Too high & 1 & 3 & 3 & 2 \\
\hline & Good & 4 & 3 & 4 & 1 \\
\hline & Too low & 0 & 0 & 0 & 0 \\
\hline \multirow[t]{3}{*}{ Colour temperature } & Too high & 0 & 0 & 0 & 0 \\
\hline & Good & 5 & 6 & 7 & 3 \\
\hline & Too low & 0 & 0 & 0 & 0 \\
\hline \multirow{3}{*}{$\begin{array}{l}\text { Is the new lighting an } \\
\text { improvement? }\end{array}$} & Yes & 3 & 4 & 5 & 0 \\
\hline & No opinion & 1 & 0 & 1 & 3 \\
\hline & No & 0 & 0 & 0 & 0 \\
\hline \multicolumn{6}{|l|}{ Effects on clients } \\
\hline \multirow[t]{3}{*}{ Activity daytime } & Decrease & 0 & 0 & 0 & 1 \\
\hline & No difference & 3 & 1 & 6 & 1 \\
\hline & Increase & 1 & 3 & 0 & 1 \\
\hline \multirow[t]{3}{*}{ Activity night-time } & Decrease & 0 & 3 & 0 & 1 \\
\hline & No difference & 4 & 1 & 6 & 1 \\
\hline & Increase & 0 & 0 & 0 & 1 \\
\hline \multirow[t]{3}{*}{ Number of falls } & Decrease & 1 & 2 & 2 & 0 \\
\hline & No difference & 3 & 2 & 4 & 3 \\
\hline & Increase & 0 & 0 & 0 & 0 \\
\hline \multirow[t]{3}{*}{ Use of sleep medication } & Decrease & 0 & 1 & 0 & 0 \\
\hline & no difference & 4 & 3 & 6 & 3 \\
\hline & Increase & 0 & 0 & 0 & 0 \\
\hline \multicolumn{6}{|c|}{ Effects on care professionals } \\
\hline \multirow[t]{3}{*}{ Physical fitness } & Improved & 1 & 0 & 0 & 0 \\
\hline & No difference & 3 & 4 & 6 & 3 \\
\hline & Worsened & 0 & 0 & 0 & 0 \\
\hline \multirow[t]{3}{*}{ Work pressure } & Improved & 0 & 1 & 0 & 0 \\
\hline & No difference & 4 & 3 & 6 & 2 \\
\hline & Worsened & 0 & 0 & 0 & 1 \\
\hline \multirow[t]{3}{*}{ Work satisfaction } & Improved & 1 & 1 & 1 & 0 \\
\hline & No difference & 3 & 3 & 5 & 3 \\
\hline & Worsened & 0 & 0 & 0 & 0 \\
\hline
\end{tabular}

Two out of the 17 care professionals clearly indicated that they noticed that the need for sleep was reduced. Four indicate that they observed a reduced activity of residents during the night. Given the health claims of the DLSs, these numbers of care professionals are low. The majority of positive experiences are found in care facility B. This is the care facility with the highest measured illuminances.

None of the 21 care professionals experienced the colour temperature of the lighting or the dynamic character of the light as unpleasant. Nine indicated that the light levels during specific times of the year were too

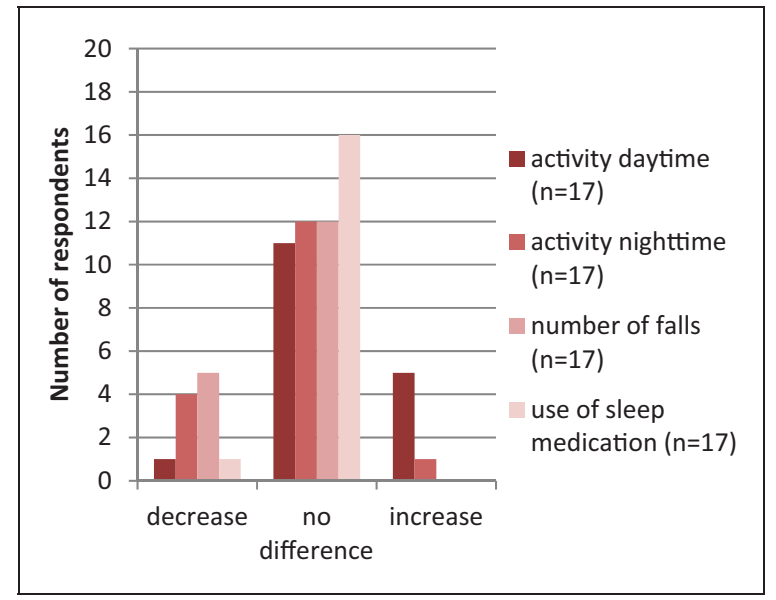

Figure 8. Observed effects of DLSs on residents.

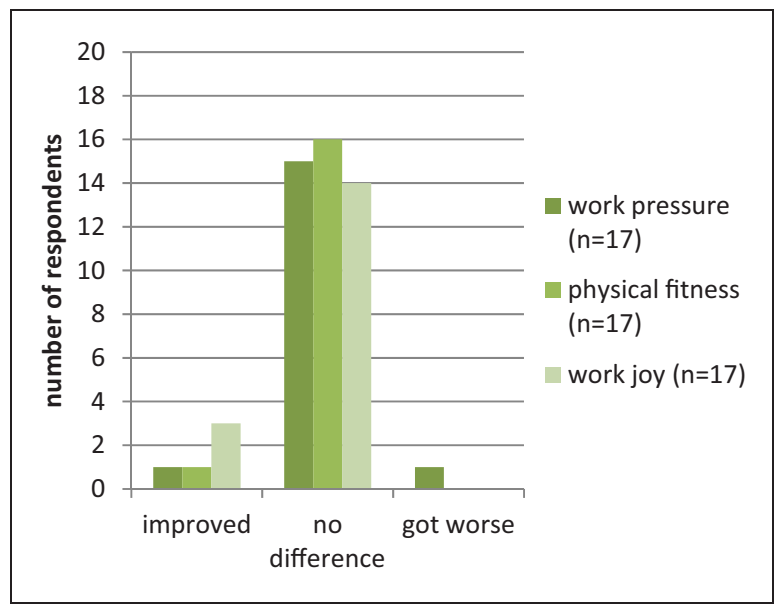

Figure 9. The influence of DLSs on care professionals.

high, for example, during a sunny day in summer (six respondents) and during the Christmas season when one expects a more intimate and cosy atmosphere (five respondents).

A majority of 14 out of the 17 care professionals indicated that they observed no difference in work satisfaction after installing the DLSs, whereas the other three thought the work satisfaction had improved (Figure 9). One of the care professionals clearly indicated that the high light levels had a positive influence on her mood. Two of the 17 experienced a difference in work pressure and one in physical fitness.

Do the installed lighting levels meet the preliminary threshold levels stated in the literature?. In four living rooms of the care facilities, the vertical illuminances and colour temperatures at the eye level were measured at places where residents were seating on a regular basis (Figure 10, for 


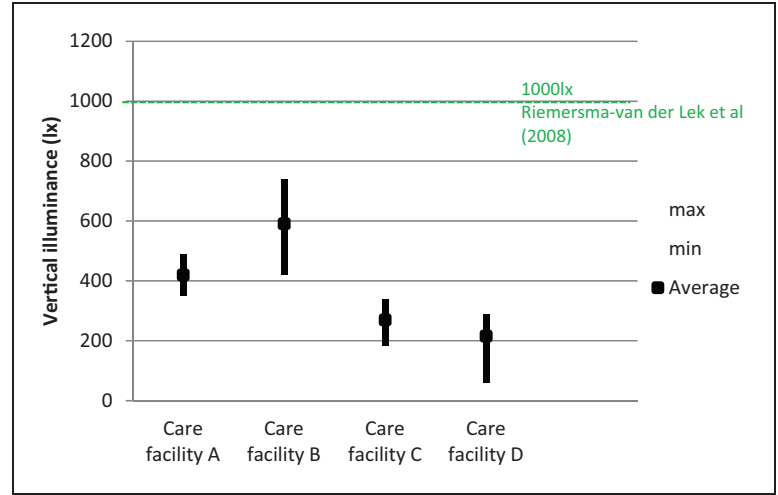

Figure 10. Average vertical illuminances (lx) per care facility - DLS only with the activating light condition.

Table 3. Vertical illuminance $\left(\mathrm{E}_{\mathrm{v}}[1 \mathrm{x}]\right)$ and colour temperature $\left(\mathrm{T}_{\mathrm{cp}}[\mathrm{K}]\right)$ per position per care facility; activating light scenario and DLSs only.

\begin{tabular}{|c|c|c|c|c|c|c|c|}
\hline \multirow{2}{*}{$\begin{array}{l}\text { Care } \\
\text { facility }\end{array}$} & \multicolumn{7}{|c|}{ Position } \\
\hline & & 1 & 2 & 3 & 4 & 5 & Average \\
\hline \multirow[t]{2}{*}{ A } & $E_{v}$ & 460 & 430 & 350 & 490 & 370 & 420 \\
\hline & $T_{c p}$ & 5900 & 6100 & 5550 & 5900 & 5700 & 5830 \\
\hline \multirow[t]{2}{*}{ B } & $\mathrm{E}_{\mathrm{v}}$ & 685 & 420 & 520 & 740 & - & 591 \\
\hline & $T_{c p}$ & 3250 & 3100 & 3200 & 3330 & - & 3220 \\
\hline \multirow[t]{2}{*}{$\mathrm{C}$} & $\mathrm{E}_{\mathrm{v}}$ & 340 & 340 & 270 & 185 & 215 & 270 \\
\hline & $T_{c p}$ & 4260 & 4305 & 4210 & 4150 & 4060 & 4197 \\
\hline \multirow[t]{2}{*}{ D } & $\mathrm{E}_{\mathrm{v}}$ & 280 & 250 & 290 & 200 & 60 & 216 \\
\hline & $T_{c p}$ & 3400 & 3430 & 3435 & 3400 & 2760 & 3280 \\
\hline
\end{tabular}

DLSs: dynamic lighting systems.

measurement positions, see Figures 2 to 5). In Table 3, the total flux as well as the colour temperature of the DLSs was set to its maximum value, the activating light condition. Table 4 shows the values during the resting time, after lunch.

\section{The illuminance of the light}

The total average vertical illuminance for the activating condition was $3701 \mathrm{x}$ while the average illuminance for the restful condition was $2171 \mathrm{x}$. In practice, the NIF effects occur due to a combination of illuminances, spectral distribution and duration and time of administering of the light.

There are large differences in illuminances not only between the different care facilities but also between the different measurement positions within a given facility. Since the position of the DLSs does not always relate to the positions in the living room where people sit on a regular basis, for example, when having their meals, the
Table 4. Vertical illuminance (E [lx]) and colour temperature $\left(\mathrm{T}_{\mathrm{cp}}[\mathrm{K}]\right)$ per position per care facility; restful light scenario and DLSs only.

\begin{tabular}{|c|c|c|c|c|c|c|c|}
\hline \multirow{2}{*}{$\begin{array}{l}\text { Care } \\
\text { facility }\end{array}$} & \multicolumn{7}{|c|}{ Position } \\
\hline & & 1 & 2 & 3 & 4 & 5 & Average \\
\hline \multirow[t]{2}{*}{ A } & $\mathrm{E}$ & 55 & 30 & 25 & 35 & 30 & 35 \\
\hline & $\mathrm{T}_{\mathrm{cp}}$ & 3020 & 3360 & 3200 & 3400 & 3350 & 3266 \\
\hline \multirow[t]{2}{*}{ B } & $\mathrm{E}_{\mathrm{v}}$ & 590 & 390 & 445 & 580 & - & 501 \\
\hline & $\mathrm{T}_{\mathrm{cp}}$ & 2850 & 2730 & 2835 & 2870 & - & 2821 \\
\hline \multirow[t]{2}{*}{$\mathrm{C}$} & $\mathrm{E}_{\mathrm{v}}$ & 340 & 340 & 270 & 185 & 215 & 270 \\
\hline & $T_{c p}$ & 4260 & 4305 & 4210 & 4150 & 4060 & 4197 \\
\hline \multirow[t]{2}{*}{$\mathrm{D}$} & $\mathrm{E}_{\mathrm{v}}$ & 75 & 60 & 65 & 60 & 40 & 60 \\
\hline & $\mathrm{T}_{\mathrm{cp}}$ & 2700 & 2750 & 2800 & 2900 & 2600 & 2750 \\
\hline
\end{tabular}

values in care facility D are extremely low (lower than $100 \mathrm{~lx}$ on position 5). This points out to a suboptimal choice of location of the installed DLSs.

If the goal of the DLSs is to support the circadian rhythmicity, it is remarkable that in none of the investigated care facilities the illuminances approach the recommended levels of $10001 x^{4,8,22,23}$ Based on these measurements, it is found that lighting levels are too low to cause the desired effects.

\section{The colour temperature of the light}

The colour temperature of lighting was measured on the same positions as the vertical illuminance. The total average colour temperature of electric light for all facilities in the activating light condition was $4130 \mathrm{~K}$ and $3259 \mathrm{~K}$ for the restful condition. These values are higher than the values found in nursing homes without special lighting equipment. ${ }^{19,20,22,23}$

Figure 11 shows the average $T_{c p}$ in the activating light condition of the four facilities as well as the minimum and maximum values. The green dotted line represents a $T_{c p}$ of $6500 \mathrm{~K}$. This is lowest value at which any positive effect was found in the scientific literature. $^{22}$ The red dotted lines are the values for which no significant effects were found. ${ }^{17,23}$ Based on the results of these studies, the $T_{c p}$ in only facility $A$ approaches the desired threshold value of $6500 \mathrm{~K}$. In facilities $B$ and $D$, the values for $T_{c p}$ do not differ much from the conventional values. In Facility $\mathrm{C}$, the values are about $1000 \mathrm{~K}$ higher.

In three of the four facilities, during rest time (just after lunch), the lighting automatically changes to a low light level and low colour temperatures. The time schedule of the lighting and the time schedule of the residents are not optimally synchronized (Table 5). This means that people rest in bright light conditions and are active during dim light conditions. 


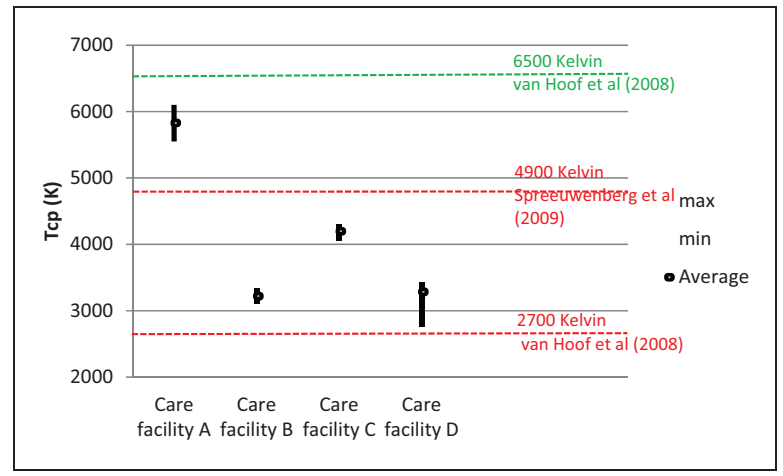

Figure 11. Average vertical colour temperature $(K)$ of the different care facilities - DLS only with the activating light condition.

Table 5. Time of low lighting levels compared to the rest time of the residents.

\begin{tabular}{lll}
\hline Facility & Rest time (h) & Dim light situation (h) \\
\hline A & $13: 30-15: 00$ & $12: 00-14: 00$ \\
B & $13: 00-14: 00$ & $14: 00-15: 00$ \\
C & $13: 00-14: 30$ & No dim light situation \\
D & $13: 00-15: 00$ & $13: 00-14: 30$ \\
\hline
\end{tabular}

\section{Discussion}

In recent years, (psycho)geriatric care facilities in the Netherlands purchased and installed DLSs. These facilities made investments in order to improve the well-being of their residents and to support care professionals in their daily tasks. The evidence supporting the installation of DLSs is still weak, and the incentives of managers for purchasing DLSs and the perception of care professionals working with these systems have not been studied before. Although this mixed-method study is only small, it provides an overview of the way DLSs are being used and what the first experiences are in practice. The suggestion is to conduct a follow-up study, involving more facilities in order to demonstrate the robustness of the results.

Based on the current data, it can be concluded that the majority of the care professionals as well as managers are positive about the DLSs. When analysing the arguments of the managers for purchasing DLSs, none of these arguments are convincingly backed by scientific data. These scientific data are not always available to managers and care professionals. Moreover, there are hardly any guidelines or standards dealing with DLSs and their implementation. A commonly used standard as EN $12464-1^{24}$ does not provide any information on the design and implementation of DLSs, even though this standard describes lighting conditions on the work floor including health care facilities. In practice, this means that there is a lack of professional guidance for architects, building services engineers and facility managers when care organizations chose to purchase and install DLSs.

\section{Answering the research questions} What was the main reason for installing
the DLSs and can the benefits of the
system counterbalance the costs? The
main argument of the managers for purchasing DLSs was to improve the general well-being of the residents as well as improving their sleep-wake rhythm. Although economic arguments are given for the purchase, none of the care facilities indicate that these are the main reasons.

The investments done by the care facilities differ strongly. Three of the six managers indicate that the costs are compensated by the benefits of the system although no data are, and could, be given. Two facilities were at the time of writing, still studying the effects, although a cost-benefit analysis is not one of the research goals. At the time the DLSs were purchased, facilities paid $€ 25,000$ and $€ 53,000$, respectively, for these systems (years 2007 and 2008). The current price level of an additional DLS is about $€ 10,000$ to $€ 15,000$ per living room for about eight residents. A total cost-benefit analysis and the incentive for purchasing may, thus, be different when made today.

The total cost of investment has a probable impact on the willingness to purchase DLSs. Investment costs of up to $€ 15,000$ per living room seem a confirmation for many decision makers of the supposed benefits. But with higher investments to be made, additional funding is necessary. Four of the six managers are all content with the lighting. One is unaware of the lighting (person who purchased has changed jobs) and one would not invest in the system again. In this facility, additional research was carried out, and, so far, no beneficial effects were found.

\section{Are care professionals and care facility managers aware of the psychological and physiological benefits DLSs should achieve?}

All six managers were aware that the DLS is computercontrolled and the dynamic character of the lighting both in illuminance level as in colour. No one was able to deliver data on the programmed light scenario(s). Two managers thought the light level was 
influenced by the available daylight. None of the 21 care professionals was aware of a variation in light level or colour of the light during the day. In three facilities, the DLS is switched on and off in the morning and evening and that it is steered by software. The ignorance of the care professionals can be explained by the fact that managers indicate that the necessity or priority for communication is low. Due to this ignorance, the DLS does not perform at its best. Psychological and physiological benefits depend partially on timing of the light exposure, but activities of occupants and the automated light scenario did not match and were not adjusted. The lighting schemes should, thus, be adjusted to the activity patterns of the residents. Also when care professionals change the set-up of the living room, the lighting remains in the original position.

\section{Did care facilities monitor the health effects of residents in the pre- and post- installation phases?}

For only one care facility, fall incidents were registered for pre- and post-installation conditions. These data were not analysed since the facility has moved into a completely new building. It is, therefore, not clear whether a change in the number of falls can be directly attributed to lighting. The three with the newest DLSs did not have pre- and post-implementation data available (yet). No objective conclusions can be drawn related to the possible health effects of DLSs, based on data gathered by the facilities.

Care professionals from almost all but one facility noticed a reduction in falls. The benefits of fall prevention are substantial. Per year, approximately 72,000 older adults in the Netherlands, visit the hospital's emergency department with fall-related injuries, ${ }^{25}$ costing up to $€ 9000$ per person. A simple calculation demonstrates that if the DLSs can prevent 1.2 to 1.5 falls a year, the investment costs are balanced out.

\section{What are the expectations of the care professionals of the effects on the behavioural symptoms of their residents and how do care professionals perceive the DLSs?}

Five of the 17 care professionals indicated to have noticed that the activity during the day increased after installing DLSs. Four seemed to notice a reduction in the nightly activity. Of the people perceiving a positive effect, three indicate that they are not certain that the DLS is responsible for the improvement. A new building, movement sensor systems, and more active guidance of the residents could also have contributed. People working in the facility where the highest illuminance was measured, seemed to notice the most positive differences. In this facility (B), the same lighting was installed as in facility $\mathrm{D}$, although the amount of luminaires and the daylight situation was different. In facility B, minor differences were noticed, indicating that the DLS does not seem to be of influence on the results. Both facilities also had, in addition to new lighting, other improvements installed at the same time. The fewest effects (1 of 17) were noticed in terms of use of medication. Since the majority of the interviewed care professionals are not involved in prescription or distribution of medication, it does not mean that there is no difference. A suggestion for a follow-up study would be to involve the nursing home's geriatricians.

The care professionals are in general very satisfied with the lighting and consider it an improvement (12 out of 17) although a majority (14) indicated that they do not perceive any direct influence of the lighting for themselves (for instance, on work pressure and mood). Six indicate that due to the lighting, the visual performance of the residents improved. It seems that the visual improvement is as large as the NIF.

\section{Do the installed lighting levels meet the preliminary threshold levels stated in the literature?}

In none of the four facilities, a vertical illuminance at eye level of $1000 \mathrm{~lx}$ or more was measured at the most frequently used sitting positions. In three out of the four facilities, the vertical illuminance at eye level (electrical lighting only), was even under $5001 \mathrm{x}$. So far, there are no studies reported in the scientific literature that found any NIF effect to take place in such low levels of white light. In facility $\mathrm{D}$, the position of the furniture was changed; however, the DLSs remained mounted in the same position. This explains the low vertical illuminances near the sitting positions of the residents. In three of the four care facilities, the maximum $T_{c p}$ is lower than $4500 \mathrm{~K}$. Also no research has indicated that these low values yield NIF effects in older persons.

van Hoof et al. ${ }^{1}$ reviewed the methodological issues related to light therapy research and pointed to the poor description of lighting equipment and light measurements in scientific studies, as well as the often neglected contribution of daylight. Many researchers studying the effects of lighting systems on older people have just referred to the type of equipment as a 'table-mounted device of 10,000 lux', which, of course, is not sufficient. Early studies ${ }^{22,23}$ provided detailed lighting measurements and complementary simulations of the places where participants were seated. This study 
further underlines the importance of adequate light measurements when studying the effects of light therapy, in whichever mode of administration. Simply trusting on the specifications given by the installer or designer does not suffice. van Hoof et al. ${ }^{1}$ specified a set of basic rules that a good description of lighting systems should fulfil, and also for those with a cycled lighting protocol.

\section{Role of the different stakeholders}

The typical process for the installation of lighting systems in the Netherlands is as follows. A care facility decides to improve the lighting of its wards. In the six facilities, the involvement of an architect was limited. Instead, an external expert company specialized in light and well-being was consulted. Only a few lighting consultancy enterprises operating in the Netherlands work on an independent basis and get paid by the hour. Most of these consultancy companies are directly (working for a manufacturer) or indirectly (getting provision from a manufacturer) related to one or more luminaire manufacturers or dealers. Therefore, the independent character of such consultancy companies is limited; they benefit from sales. The next step is to determine an electrical installation company. This company calculates the costs of installation as well as the described luminaires, controls, etc. The consultancy company makes the lighting control scheme; the installation company does the programming. When the lighting is installed, aftersales take place by the consultancy company to check if the lighting system functions properly. The installation company remains the first party to contact for the care facility company. The electrical installer, the care facility manager and the care facility staff in general lack the needed know-how, and rationale behind the DLS and its dynamic scheme. This explains why we noticed that (the position of) the DLS was not altered when the situation in the living room was changed. If the electrical installer should gain the necessary insight and know-how, his role in the process can be much larger, both the role in the advice procedure as well as in the maintenance of the system. This may lead to better-performing DLSs, presumably resulting in the validation of the claims of the systems' benefits.

Despite the malfunctioning of the DLSs and the lack of objectively measured effects, managers and care professionals have a positive attitude towards DLSs in their facilities. Based on the short survey, subjective responses are biased towards positive outcomes, although these cannot be backed by any objective data or research. When comparing the practice of DLSs to pharmaceutical research, where both the substance and doses are reported in great detail and extensive testing is done with participants, DLS practice should be met with a more critical attitude.

A well set-up trial, in several care facilities where DLSs are installed should demonstrate the actual effects of these DLSs. This should also include objective measures since the opinion of the staff of care facilities is already partly biased and subjective. The suggestion is also to involve another stakeholder, namely the geriatrician of the facility. A geriatrician is responsible for the administration of medication, and has access to prescription records.

\section{International context}

This study has been conducted in the Netherlands. There are of course more countries in which ambient bright light or DLSs are used and tested in geriatric care settings, such as the ambient bright light systems described by Rheaume et al., ${ }^{26}$ Sloane et al. $^{27}$ and Hickmann et al. ${ }^{28}$ Most of these studies, however, focus on the therapeutic outcomes of these lighting systems and not on the technical specifications of these studies or whether the lighting systems meet the pre-set conditions in practice. As mentioned before, van Hoof et al. ${ }^{1}$ pointed to the poor description of lighting equipment and light measurements in scientific studies on therapeutic outcomes of the lighting intervention. In countries such as the United Kingdom, the main research focus is on vitamin $\mathrm{D}$ when lighting is installed in nursing homes. $^{29}$

\section{Conclusions}

The main reason for purchasing DLSs was due to the assumption that the well-being and rhythmicity of residents can be improved. Care professionals are often unaware of the supposed benefits of the DLSs. The light values measured in the participating care facilities do not exceed the minimum threshold values reported in the literature for proper vision and NIF effects. Therefore, it seems illogical that the DLSs in the researched care facilities will have any positive health effects on the residents.

\section{Authors' contribution}

All authors contributed equally in the preparation of this manuscript.

\section{Acknowledgements}

Stichting KIEN, Knooppunt Innovatie Elektrotechniek Nederland, in Eindhoven, is thanked for the financial support. All (psycho)geriatric care facilities, their managers/directors and care professionals, are thanked for their time and willingness to participate in this study. 


\section{References}

1. van Hoof J, Westerlaken AC, Aarts MPJ, Wouters EJM, Schoutens AMC, Sinoo MM and Aries MBC. Light therapy: methodological issues from an engineering perspective. Health Care Technol 2012; 20(1): 11-23.

2. van Hoof J, Wouters EJM, Schräder B, Weffers HTG, Aarts MPJ, Aries MBC and Westerlaken AC. Chapter 21. Intelligent light therapy for older adults: ambient assisted living. In: Agah A (ed.) Medical Applications of Artificial Intelligence. Boca Raton, FL, USA: CRC Press/Taylor \& Francis Group, 2013, pp.341-351.

3. van Hoof J, Kort HSM, Duijnstee MSH, Rutten PGS and Hensen JLM. The indoor environment and the integrated building design of homes for older people with dementia. Build Environ 2010; 45(5): 1244-1261.

4. van Someren EJW, Kessler A, Mirmiran M and Swaab DF. Indirect bright light improves circadian rest-activity rhythm disturbances in demented patients. Biol Psychiatry 1997; 41(9): 955-963.

5. Berson DM, Dunn FA and Takao M. Phototransduction by retinal ganglion cells that set the circadian clock. Science 2002; 295(5557): 1070-1073.

6. Brainard GC, Rollag MD and Hanifin JP. Photic regulation of melatonin in humans: ocular and neural signal transduction. $J$ Biol Rhythms 1997; 12(6): 537-546.

7. Brainard GC, Hanifin JR, Greeson JM, Byrne B, Glickman G, Gerner E and Rollag MD. Action spectrum for melatonin regulation in humans: evidence for a novel circadian photoreceptor. J Neurosci 2001; 21(16): 6405-6412.

8. Riemersma-van der Lek RF, Swaab DF, Twisk J, Hol EM, Hoogendijk WJG and van Someren EJW. Effect of bright light and melatonin on cognitive and noncognitive function in elderly residents of group care facilities. A randomized controlled trial. J Am Med Assoc 2008; 299(22): 2642-2655.

9. Forbes D, Culum I, Lischka AR, Morgan DG, Peacock S, Forbes $\mathbf{J}$ and Forbes $\mathbf{S}$. Light therapy for managing cognitive, sleep, behavioural, or psychiatric disturbances in dementia. Cochrane Database Syst Rev 2009; Issue 4: CD003946.

10. Shikder S, Mourshed M and Price A. Therapeutic lighting design for the elderly: a review. Perspect Public Health 2012; 132(6): 282-291.

11. Webb AR. Considerations for lighting in the built environment: non-visual effects of light. Energy Build 2006; 38(7): 721-727.

12. Rea MS, Figueiro MG and Bullough JD. Circadian photobiology: an emerging framework for lighting practice and research. Lighting Res Technol 2002; 34(3): 177-187.

13. Figueiro MG. A proposed $24 \mathrm{~h}$ lighting scheme for older adults. Lighting Res Technol 2008; 40(2): 153-160.

14. Barroso A and den Brinker B. Boosting circadian rhythms with lighting: a model driven approach. Lighting Res Technol 2013; 45(2): 197-216.
15. Spreeuwenberg MD, Willems C, Verheesen H, Schols J and de Witte L. Dynamic lighting as a tool to influence the day-night rhythm of clients with psychogeriatric disorders: a pilot study in a Dutch nursing home. J Am Geriatr Soc 2010; 58(5): 981-982.

16. Sleegers PJC, Moolenaar NM, Galetzka M, Pruyn A, Sarroukh BE and van der Zande B. Lighting affects students' concentration positively: findings from three Dutch studies. Lighting Res Technol 2013; 45(2): 159-175.

17. Barkmann C, Wessolowski $\mathrm{N}$ and Schulte-Markwort $\mathrm{M}$. Applicability and efficacy of variable light in schools. Physiol Behav 2012; 105(3): 621-627.

18. de Kort YAW and Smolders KCHJ. Effects of dynamic lighting on office workers: first results of a field study with monthly alternating settings. Lighting Res Technol 2010; 42(3): 345-360.

19. Sinoo MM, van Hoof J and Kort HSM. Lighting conditions for older adults in the nursing home: assessment of environmental illuminances and colour temperature. Build Environ 2011; 46(10): 1917-1927.

20. Aarts MPJ and Westerlaken AC. Field study of visual and biological light conditions of independently-living elderly people. Gerontechnology 2005; 4(3): 141-152.

21. van Hoof $\mathbf{J}$ and Verkerk MJ. Developing an integrated design model incorporating technology philosophy for the design of healthcare environments: a case analysis of facilities for psychogeriatric and psychiatric care in the Netherlands. Technol Soc 2013; 35(1): 1-13.

22. van Hoof J, Aarts MPJ, Rense CG and Schoutens AMC. Ambient bright light in dementia: effects on behavior and circadian rhythmicity. Build Environ 2009; 44(1): 146-155.

23. van Hoof J, Schoutens AMC and Aarts MPJ. High colour temperature lighting for institutionalised older people with dementia. Build Environ 2009; 44(9): 1959-1969.

24. CEN.EN 12464-1. Light and lighting - Lighting of work places Part 1: indoor work places. Brussels, Belgium: Comité Européen de Normalisation CEN, 2011.

25. Hartholt KA. Falls and drugs in the older population: medical and societal consequences. Dissertation, Erasmus University Rotterdam, Rotterdam, the Netherlands, 2011.

26. Rheaume YL, Manning BC, Harper DG and Volicer L. Effect of light therapy upon disturbed behaviors in Alzheimer patients. Am J Alzheimer's Dis 1998; 13(6): 291-295.

27. Sloane PD, Williams CS, Mitchell CM, Preisser JS, Wood W, Barrick AL, Hickman SE, Gill KS, Connell BR, Edinger J and Zimmerman S. High-intensity environmental light in dementia: effect on sleep and activity. $J$ Am Geriatr Soc 2007; 55(10): $1524-1533$.

28. Hickman SE, Barrick AL, Williams CS, Zimmerman S, Connell BR, Preisser JS, Mitchell CM and Sloane PD. The effect of ambient bright light therapy on depressive symptoms in persons with dementia. J Am Geriatr Soc 2007; 55(11): 1817-1824.

29. Habell M. Specialised design for dementia. Perspect Public Health 2013; 133(3): 151-157. 